\title{
Zermeño, Sergio
}

\section{México : ¿todo lo social se desvanece?}

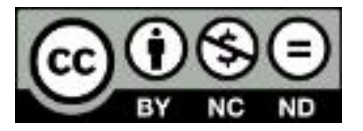

Esta obra está bajo una Licencia Creative Commons Argentina.

Atribución - No Comercial - Sin Obra Derivada 2.5

https://creativecommons.org/licenses/by-nc-nd/2.5/ar/

Documento descargado de RIDAA-UNQ Repositorio Institucional Digital de Acceso Abierto de la Universidad Nacional de Quilmes de la Universidad Nacional de Quilmes

\section{Cita recomendada:}

Zermeño, S. (2000). México: ¿todo lo social se desvanece? Revista de ciencias sociales, (11), 9-34. Disponible en RIDAA-UNQ Repositorio Institucional Digital de Acceso Abierto de la Universidad Nacional de Quilmes http://ridaa.unq.edu.ar/handle/20.500.11807/1148 


\section{México: ¿todo lo social se desvanece?}

\section{Sergio Zermeño*}

Sin duda la imagen que mejor expresa la situación por la que atraviesan una serie de países no centrales, fuertemente expuestos a procesos de apertura y globalización, es la de un desorden generalizado que está conduciendo a una fragmentación de la escena social y a una pulverización de las identidades colectivas. Indonesia, Colombia, México, Centroamérica, Venezuela, la propia Rusia, Argelia, para ya no citar otros casos más dramáticos de desmantelamiento institucional, están llamando la atención sobre el desorden acelerado y la forma abrupta y poco inteligible con que ha irrumpido el proceso de globalización y las poderosas leyes del libre mercado mundial. Esto se agrava cuando se trata de agregados sociales mal protegidos geográficamente, mal preparados técnica y culturalmente para acoplarse a esos nuevos ritmos y en donde, además, no se han aplicado políticas compensatorias (como fue el caso en la Comunidad Económica Europea para aminorar las desigualdades entre los países que se fueron integrando al pacto regional). Muy lejos de esto, en los países de la globalización salvaje, ninguna fuerza, ni el Estado nacional mismo, se preocupa por integrar a esos enormes conglomerados poblacionales, igualmente característicos de los sectores populares que de los sectores medios, arrasados por el nuevo desorden mundial.

Los efectos sobre la correlación entre la sociedad civil, el Estado y las instituciones políticas han sido innumerables y a

\footnotetext{
* Profesor-Investigador del Instituto de Investigaciones Sociales de la Universidad Nacional Autónoma de México.
} 
ello estaremos dedicando este ensayo. Uno de esos efectos que podemos enumerar desde ahora muestra a crecientes segmentos poblacionales recreando relaciones más bien verticales, caciquiles y caudillescas de vinculación entre lo social, atomizado y endeble, y lo político, y todo ello en detrimento de la ciudadanización, de aquellas formas de organización que no hace mucho permitian presagiar, con una intención ética irreprochable, una transición inminente a la democracia social (a formas democráticas más civilistas, más horizontales, productoras de tejido social y "empoderamiento" de la sociedad civil). En la segunda parte del ensayo nos preguntaremos por las posibilidades y las técnicas con que cuenta un partido democrático y de izquierda como el PRD y una administración como la de Cuauhtémoc Cárdenas en la capital del país para reforzar un tejido social en estas condiciones.

Ante un panorama tan poco halagüeño y con una expectativa más bien baja en torno a posibilidades alternativas de desarrollo económico para la región latinoamericana, por decir lo menos, las ciencias sociales están atestiguando el ascenso de los proyectos y de las preocupaciones en torno a lo local. El planteamiento consiste en que ante el poder aparentemente sin contrapeso de las leyes del mercado y de los grandes capitales del mundo globalizado, la sociedad civil sólo puede oponer su fuerza identitaria, es decir, la recreación, ahí en donde aún no está completamente roto el tejido social, de formas compartidas tendientes a la construcción y defensa de identidades colectivas y mecanismos de interacción y comunicación, que tengan como resultado el embarnecimiento del poder social; pero el planteamiento agrega que el camino privilegiado para acercarse a esto tiene que tomar en cuenta el hecho de que los esfuerzos productivos, culturales, de organización ciudadana, política, religiosa, etcétera, siempre lograrán un mejor éxito cuando se encuentran enraizados territorialmente la gente pertenece a un lugar, tiene noción de los límites de lo que considera su espacio colectivo social y lo defiende, es capaz de invertir una parte de sus recursos en afecto, no se limita al mero cálculo privado, al mero interés con respecto a fines per- 
sonalizados y considera como mayor ganancia el apoyo compartido, la solidaridad grupal ante la amenaza exterior y ante la violencia generalizada que se han convertido en el distintivo de nuestra época).

Quizás por esto, que parece tan inocente, tan recogido en lo social, tan poco conspirativo, a los mexicanos y a los observadores extranjeros nos han impactado las masacres y el desmantelamiento de los llamados municipios autónomos zapatistas de Chiapas y sus poblados (Acteal, Chenalhó, Tierra y Libertad, Taniperla, ...); increíblemente, todo el poder del Estado nacional y regional parece estar siendo empleado en una cruzada en la que el ejército, las policías y los grupos paramilitares masacran a una población mayoritariamente indígena, paupérrima, que ha cometido el error de nombrarse autonomista y que simpatiza con el zapatismo intentando de esa manera recobrar el control sobre sus medios de subsistencia y de autoridad cultural y política, alguna forma de identidad colectiva en una situación social que está muy cerca de la inanición, de la renuncia total a seguir adelante. Han sido destrozados una decena de municipios autónomos y algunos de ellos lo fueron a menos de 24 horas de que en aquella entidad el Presidente Zedillo afirmara que "entre mexicanos no puede haber vencidos ni vencedores", que "no usaría la fuerza para resolver el conflicto" y que "el gobierno no apuesta a erosionar las bases sociales de nadie."

Tendremos que preguntarnos qué sucede en la época actual y con particular severidad en las sociedades dependientes, altamente desiguales e históricamente autoritarias (comenzamos a ser el gran ejemplo); por qué en estos casos se vuelve groseramente nítido el maridaje entre la sofisticada técnica de los medios masivos de comunicación, los sistemas de gobierno y sus clientelas consentidas, los aparatos de coerción policiacos, militares y paramilitares, los grandes capitales nacionales y trasnacionales y los gobiernos de las naciones más desarrolladas y poderosas del orbe. ¿Qué sucede que a partir de ese espectro, de esa concentración de poder, se ha establecido un control sobre los destinos de las comunidades, de los munici- 
pios, de lo local y de lo regional de manera que estos últimos niveles son prácticamente despojados de cualquier fuerza, de cualquier autonomía para regir y orientar su vida colectiva?

Sea como sea, una cosa es cierta: la tensión preponderante de nuestra época parece estar dándose entre ese núcleo duro del poder nacional y transnacional, por un lado, y todos aquellos territorios, regiones, comunidades, etnias, poblados, etc., que han decidido refugiarse de la intemperie globalizadora y que para ello han escogido el último de los derechos: el recogimiento en sí mismos, en lo local, alguna forma de autonomía, alguna reconstrucción de la identidad circunscrita a la comunidad, cuando eso todavía es posible; nos sobran ejemplos: el poblado de Tepoztlán en el sureño estado de Morelos ilustra de manera nítida el despojo de territorios y de recursos naturales a las comunidades, bajo el disfraz de moda: clubes de golf rodeados de inmensos proyectos urbanísticos y turísticos (al oponerse los pobladores a este destino y organizarse, recibieron como respuesta un listado de órdenes de aprensión para todos sus dirigentes); otro ejemplo: el proyecto trasatlántico atravezando el Istmo de Tehuantepec, en competencia con el Canal de Panamá, con su alucinante técnica de fletes interoceánicos y su macroregión maquiladora se confronta con la poderosa identidad de juchitecos-zapotecos que se oponen a ser convertidos en masa de estibadores y ensambladores; un ejemplo más: la infinidad de municipios de Oaxaca y Guerrero que se plantean como único objetivo el reencontrar su autodeterminación y buscan por todos los medios algo que hacer, que ofrecer, aunque sea muy poco frente a la oferta mundial, a pesar de que toda la juventud de esos espacios está migrando hacia el norte y las grandes ciudades; los municipios autónomos de Chiapas, por citar el caso más dramático, que aunque no gravitan en los circuitos económicos mundiales hay que extirpar obviamente, porque cualquier autodeterminación es un mal ejemplo; enormes regiones de Veracruz y Tabasco, en fin, que no quieren convertirse en páramos sembrados con esos ecológicamente devastadores eucaliptos sólo para favorecer a las grandes empresas papeleras; infinidad de espacios de participación vecinal en el D.F., 
podriamos agregar, que exigen la descentralización y el recogimiento en áreas subdelegacionales desde las que sea más fácil buscar soluciones a la seguridad, al abasto, al agua, a la educación, etc., a lo que se ha opuesto el partido oficial con toda su herencia centralizadora y estatista.

La fragmentación, un fenómeno global

Coloquemos todo esto, sin embargo, en un marco global: desde los años setenta puede ser demostrado en todas partes y no sólo en México un aumento cuantitativo de la fragmentación, de la pulverización de la violencia desorganizadora y, también, un cambio cualitativo. Baste aquí con citar al intelectual alemán Hans Magnus Enzesberger cuando nos recuerda que lo significativo de la violencia hoy resulta ser el que ya no se ejerce fundamentalmente por fuerzas organizadas, quizás jerarquizadas, enfrentándose a un orden externo a ellas, sin duda opresor, y también organizado y jerarquizado, fuerzas en la mayoría de los casos tenientes de los aparatos del poder político o militar o enfrentadas a ese aparataje (y nos trae a la memoria la imagen más temida hasta hace pocos años: la Tercera Guerra Mundial a cargo de las superpotencias atómicas).

A partir de la caída del Muro de Berlín, los conflictos nos muestran otro rostro: se trata de la guerra de todos contra todos, en donde incluso la guerrilla y la antiguerrilla cobran autonomía con respecto a los grandes principios ideológicos y éticos con que justificaron no hace mucho su llamado a las armas: no va quedando más que una chusma armada, convertida en bandas de asaltantes: "ya no hay una meta, un proyecto o una idea que los cohesione, sino más bien una estrategia: robo, muerte y saqueo... Nadie que no sea un especialista, agrega Enzensberger, puede aprender de memoria las 150 etnias que ha liberado el derrumbe de la Unión Soviética... Debemos preocuparnos por sectas islámicas, milicias africanas y fracciones camboyanas, cuyas razones politicas son y permanecen incomprensibles."1 Esto conduce a que el espec- 
tador se sienta inerme e incapaz, se encapsule y se desconecte rechazando o negando aquellos actos de solidaridad que, desde su espacio disperso y atomizado, sabe que no tendrán ningún efecto ante la injusticia y la violencia.

La dispersión en sociedades desarticuladas

Ahora bien, lo que debemos destacar, dejando el plano global, es que estas tendencias hacia la pulverización y la atomización cobran ritmos frenéticos en las sociedades cuyo acoplamiento a la modernidad ha sido truncado y deficiente por varias razones: por un proceso de mestizaje poco acorde a las exigencias de esa misma modernidad; por un abrupto pasaje de la sociedad campesina a la sociedad urbana en sólo cuatro décadas de crecimiento salvaje con los consecuentes desbalances culturales y demográficos que hoy tenemos a la vista; por la manera en que todo ese dinamismo se estrelló contra el muro del estancamiento que desde los años ochenta ha vuelto nulo el crecimiento en México y en otras naciones; y, en fin, por las políticas económicas neoliberales que nos dejan sin defensas en una economía abierta y globalizada (una economía de frontera con la más poderosa nación del mundo), incapacitados para mantener los más mínimos "nichos" a salvo del intercambio trasnacional.

En tales casos, las tendencias dispersoras y atomizantes propias de las sociedades post-industriales de alto desarrollo se ven redobladas por influjos disgregadores poderosísimos.

1. En el caso mexicano, entre cinco y diez millones de campesinos maiceros, en un lapso brevísimo que no llega a los diez años, han pasado a ser agentes económicos inservibles en ese rol tradicional, sobre todo desde la entrada en vigor del TLC que ha permitido la importación de ese grano a la mitad de precio

1 Enzenberger, Hans Magnus, "Todos somos la guerra civil", Nexos, 189, IX, 1993, p. 24. 
desde los Estados Unidos. La migración y las corrientes de jornaleros en todo el país y hacia el país del norte se vuelven entonces un fenómeno irrefrenable que se manifiesta en pueblos fantasmas del Altiplano y del Sur, casi sin hombres y mujeres en edad de trabajar, y grandes ciudades en crecimiento acelerado que son polos de atracción por el espejismo de algunos de sus servicios, pero que son incapaces de ofrecer empleos mínimamente productivos. ${ }^{2}$

2. Otro tanto vemos que acontece en la franja fronteriza del norte mexicano con las jovencitas de entre 15 y 24 años que trabajan en la maquila o ensamblaje de productos con procedencia y destino norteamericanos. Serán un millón en el año dos mil, la tercera parte de la población manufacturera mexicana, pero gravitan en su entorno muchos millones de compatriotas, desde sus deshilvanadas y rotas familias hasta la improvisada infraestructura de servicios y transporte que acompaña esos anómicos y desordenados panoramas urbanos; ahí, millones y millones de mexicanos en vías de pauperización y desmantelamiento acelerado de sus colectivos de origen, nos muestran ya la faz horrenda de uno de los pocos renglones "exitosos", junto con la exportación petrolera, de esta globalización dependiente. ${ }^{3}$

3. El propio empresariado sufre este efecto pulverizante en la medida en que, por una parte, en unas cuantas empresas trasnacionales poderosísimas se concentra el dinamismo y las ganancias mientras que su estructura intermedia se difumina vencida por una competencia sin fronteras, o desaparece en favor del mundo informal y los talleres clandestinos acicateados por el abaratamiento de los fletes, el contrabando y la subcontratación de procesos otrora integrantes de la cadena productiva fabril.

2 Losé Luis Calva, La Jornada, 16 de noviembre, 1991.

3 Cirila Quintero, "Sindicalismo subordinado e industria maquiladora en Tijuana”, Estudios Sociológicos, num. 21, sept.-dic., 1989. 
"Siete millones de personas pasarán a la economía informal donde ya laboran 7 millones de personas, presagiaba amenazante el dirigente del Instituto Mexicano de la Pequeña y Mediana Industria en 1997, si el gobierno no renegocia las deudas tributarias de este sector". Para qué citar a esa otra parte del empresariado, la del comercio establecido, que sucumbe frente al mar de vendedores ambulantes cuya competitividad estriba en no pagar alquileres ni impuestos, vender en muchos casos productos piratas y tener una "disposición" para abatir el margen de sus ganancias hasta la ignominia, con tal de vender algo. En este sentido Carlos Salinas de Gortari logró en sólo seis años lo que más de un siglo de socialismo internacional fue incapaz de realizar: acabar con la burguesía nacional.

4. ¿Cuántos talleres clandestinos, cuántas costureras en sus domicilios, y qué grado ha alcanzado la explotación extrema de esos espacios familiares de la subcontratación en la industria del vestido, de la alimentación, de los productos del cuero, de los juguetes y las baratijas... ¿cómo medir el crecimiento de ese universo infinito en una economía que se achica, que excluye, que inventa sus propias estadísticas, que corrompe a intelectuales, medios de comunicación y profesionistas para generar una imagen positiva de este proceso de regresión humana?

5. En cuanto a la mano de obra industrial, ese gran actor de la modernidad que en nuestro país parecía finalmente embarnecer hacia los años setenta, con sus demandas de autonomía organizativa e independencia sindical; de él y de sus organizaciones francamente queda muy poco: las empresas no estratégicas se encuentran en condiciones de tal debilidad que ante las exigencias salariales o ante las amenazas de huelga, prefieren quebrar, lo que desanima la acción asociada de los trabajadores. Cuando las empresas son estratégicas como la del automóvil, las maquiladoras o la petrolera, simplemente se pone en marcha la ingeniería desmanteladora de la organización colectiva o se echa mano de las guardias blancas, la requisa, las fuerzas policiacas o los militares para reprimir sin misericordia 
cualquier protesta. Desde el momento en que las grandes firmas automotrices durante los años ochenta se mudaron de la ciudad de México y del centro del país hacia el norte para facilitar sus exportaciones, quedó claro que su mano de obra sería mejor capacitada para hacerse cargo de las nuevas tecnologías de punta, pero al mismo tiempo quedó claro que había perdido su tradición laboral (ya no fueron hijos de obreros del automóvil quienes ahí se emplearon), sus salarios cayeron a casi la mitad con respecto al centro del país (a pesar de su mayor calificación), y su organización gremial fue prácticamente erradicada y severamente regulada por la empresa y los gobiernos regionales. De las pobres obreras maquiladoras ni hablar: sólo una de cada tres está adscrita a un sindicato, pero de entre las que lo están, en ocho de cada diez casos son incapaces de mencionar el nombre de su representante sindical. Obviamente el asunto se complica por el hecho de que cada una de esas trabajadoras se muda varias veces de empresa en un sólo año. Ahorrémonos las escenas en el medio obrero petrolero: aquí y en general en las empresas gubernamentales, el sindicato actúa descaradamente, y sin las recompensas del periodo populista, como un instrumento de represión cruda de sus agremiados.

6. Cuando los lazos primarios y los elementos cohesionadores de la tradición han sido de esta manera pulverizados o reducidos al folklore, el individuo se encuentra proclive a una cierta soledad, a un estado de indefensión que se puede convertir fácilmente en terror personalizado Hay que voltear solamente hacia ese panorama de competencia salvaje, de todos contra todos, en que se ha convertido el desempleo, ese invitado de honor del neoliberalismo para abaratar el costo de la mano de obra y producir artículos comprables a precio competitivo en la feria global. Nos encontramos entonces ante una masa de trabajadores inermes, que obedecen a los dictados de su razón individual y que buscan empleo a toda costa, dispuestos a cualquier concesión, desorganizados e inorganizables y en condiciones inminentes de delincuencia: lo que otrora fue considerado como medidas represivas intolerables, apa- 
rece entonces como acertadas decisiones del poder público (viene al caso recordar el éxito que ha tenido en ciudades como Nueva York el programa policiaco "cero tolerancia”). ${ }^{4}$

Hay pues, en la base de la pirámide, una masa dispersa y creciente de excluidos que no dispone de los canales legitimos para comer, que ganan una miseria y cuyos salarios son cada vez más reducidos (el poder adquisitivo del salario mínimo en 1996 es de sólo la tercera parte con respecto al de 1981 último año antes de la ortodoxia neoliberal); hoy ese salario mínimo sólo cubre el $15 \%$ de la Canasta Normativa de Satisfactores Esenciales, indicador que separa oficialmente a los pobres de los no pobres. Pero lo verdaderamente increíble es que 3 de cada 10 mexicanos ganan hasta un salario mínimo y otros tres de esos mismos diez ganan hasta dos salarios mínimos. En el caso de los jóvenes (15 a 25 años) esto se agrava porque los índices de desempleo abierto son hasta cuatro veces mayores que entre los adultos. ${ }^{5} \mathrm{Si}$ una jornada completa de trabajo en seis de cada diez mexicanos no da más que para mantenerse en la pobreza profunda, el trabajo, en efecto, no podrá seguir manteniéndose en nuestra sociedad como un valor positivo. "Lo sorprendente en estas condiciones es que tantos jóvenes sigan trabajando". 6

4 Entonces cobran todo su sentido las estadísticas de la violencia: en aquellas regiones periféricas de las grandes ciudades en donde el desempleo y el subempleo son enormes, en donde un alto número de familias están rotas, en donde la escolaridad es pésima, los datos son elocuentes: durante 1995 los homicidios intencionales en el D.F. constituyeron menos del uno por ciento del total de delitos registrados $(0.55 \%)$, mientras que en el área urbana aledaña a la capital representaron casi tres veces más (1.56\%); otro dato: el homicidio doloso por golpes es 6.2 veces más frecuente en la zona conurbada; en cuanto a los homicidios que resultan de accidentes de transporte en la periferia urbana hay 13.3 veces más muertos que en la capital federal. En fin, por cada cien violaciones ocurridas en el D.F., los municipios aledaños registraron 143, pero por cada cien tentativas de violación denunciadas en el D.F. allá se registraron 720. Ruiz Harrel, Rafael, "La zona metropolitana: un reporte", Reforma, 21 de octubre, 1996, p.2b. Hay una correlación evidente entre atomización, anomia, hábitats construidos al vapor, movilidad salvaje, desempleo, etc.

5 INEGI, Conteo de población y vivienda, 1995.

6 Boltvinik, Julio, "Desvalorización del trabajo y delincuencia”, La Jornada, 31 de oct. de 1997. 


\section{Desbalance y disolvencia de los colectivos}

Pero veamos los efectos perversos de esta pulverización y de esta desaparición del espacio público llevando la hipótesis general a terrenos más concretos: ante el desorden y la violencia, cada actor, cuando aún está en posibilidad de hacerlo, toma medidas defensivas que terminan por agravar la tendencia disgregadora:

7. Hoy constatamos, incrédulos, que los miembros de lo que alguna vez fueran movimientos sociales vigorosos, surgidos por demandas de grupos organizados o por tragedias naturales, como el terremoto de 1985 en el DF, se disgregan también en infinidad de subconjuntos, pues intuyen con razón que las nuevas condiciones del juego político (al menos hasta antes de las elecciones del 97 en la Capital), vuelven a los liderazgos extremadamente vulnerables y corruptibles (los vendedores ambulantes que alguna vez tuvieron lideresas casi únicas y casi incorruptibles, optan por apoyar a pequeños jefes negociando acuerdos de corta duración. De alguna manera sucede lo mismo con los deudores de la banca, los miembros de los movimientos urbano-populares, las organizaciones campesinas, indígenas, etcétera); ¿Cómo apartar de todo esto el espectáculo extremo al que llegamos en el año de 1995, cuando en un sólo día tuvieron lugar cien marchas en el Distrito Federal? (imagen dramáticamente posmoderna).

8. Citemos en nuestro catálogo de la pulverización el ejemplo quizás más relevante: la utopía salinista de convertir la relación entre el dirigente (Salinas) y sus gobernados en un asunto personal: el líder indiscutido relacionándose, sin instituciones ni aparatos de mediación, con pequeños núcleos de ciudadanos regados por todo el país, llamados "comités de solidaridad", sin identidad consistente ni continuidad organizativa, congregados de manera pasajera para construir el drenaje de la cuadra, las banquetas, etc., pero sobre todo, para servir sin mediaciones al poder, al vértice de la pirámide. 
9. Llevando la hipótesis a terrenos aún por comprobar, ¿podría establecerse que las bandas juveniles que tanto alarmaron a las clases medias y a la televisión durante los setenta y los ochenta y que estaban compuestas por 10 o 15 elementos, según lo comprobamos en una investigación, ${ }^{7}$ hoy se achican porque se descubren, en sus dimensiones originales, vulnerables ante la policía y lentas en su accionar? Quizás lo que sí es comprobable ya, cambiando de escala, es que mientras todos los esfuerzos se concentraban en combatir a los tres grandes cárteles mexicanos (Juárez, el Golfo y Tijuana), han surgido nuevas y pequeñas bandas por todos lados, vendiendo no sólo kilos sino toneladas de estupefacientes. ${ }^{8}$

\section{Destrucción deliberada de las identidades colectivas}

Pero recordemos que más allá de las tendencias estructurales hacia la pulverización se suman, como lo establecíamos al inicio de este ensayo, aquellos actos deliberados (producto de la voluntad), venidos desde el Estado y dirigidos al desmantelamiento de las identidades y los colectivos sociales. El Estado, argumentando el bien de la nación (el bien de los vencedores del libre comercio), se lanza de manera deliberada a la disolución de todos aquellos núcleos duros de identidad colectiva, desde el barrio hasta la región, desde el sindicato hasta las universidades, que se oponen a los planes de apertura, competitividad, privatización, recorte de subsidios o de personal, etc.: clubes de golf, proyectos interoceánicos, municipios indígenas...

Como ya se vuelve obvio, no sólo el referente a la comunidad, a la identidad colectiva, a la autonomía... se disuelven molecularmente dando paso a una especie de extracción y muerte del poder social, sino que lo mismo puede establecerse

7 Castillo, Héctor, Sergio Zermeño y Alicia Zicardi, "Juventud popular y bandas en la Ciudad de México", en García Canclini, Nestor (Comp.), Cultura y Pospolitica, Consejo Nacional para la Cultura y las Artes, México, 1995.

8 Informe del Instituto Nacional para el Combate a las Drogas, La Jornada, 25 de enero, p.8. 
en lo referente a todos los espacios constitutivos de lo público: esos medios concurridos por los ciudadanos para interactuar comunicativamente, podríamos decir, abusando de Habermas:

10. Así, la ola privatizadora, desconcentradora y atomizante debe ser leída igualmente en el terreno de la educación (en el que se ha vuelto obvio que la ideología de la "excelencia" resume el elitismo y la exclusión), en el de la seguridad social o en el del abasto. Hemos visto incrédulos cómo clínicas privadas coludidas con empresas financieras se limitan a explicarle a los pacientes que el monto de sus cotizaciones (de aquellos que aún se encuentran en la economía formal y las han cubierto), les da derecho sólo a tal tipo de curas, pero no a tal otro, que se encuentra fuera de sus cuotas de ahorro para la salud, para el retiro o para la muerte. Del campo de la salud se amputa su componente solidario, que fue su distintivo primordial, para caer en el egoísmo, en el individualismo: "yo cotizo tanto y tengo este seguro privado, tu a ver cómo le haces”.

11. El abasto, por ejemplo, ese acto solidario de distribuir productos de primera necesidad a precios bajos y que en otras sociedades, incluso desarrolladas, funciona perfectamente, no fue jamás objeto de modernización administrativa, de eficientización, de contraloría y auditoría sino que fue desmantelado conservándose sólo los renglones alimentarios de leche y tortillas, es decir, aquellos asuntos en torno a los cuales podría generarse la asociación colectiva para la sobrevivencia o, en el extremo, los amotinamientos. El ex presidente Carlos Salinas buscó por todos los conductos destruir la solidaridad en la academia, en la seguridad social, en el abasto, etc., pero tuvo el cinismo de conservar la palabra "solidaridad" para su propio y muy personal partido político, el Programa Nacional de Solidaridad (PRONASOL): esa colección de átomos fugaces regados por todo el país, más de doscientos mil comités de solidaridad, que por grupos iban cada lunes a visitarlo a la casa de gobierno, a relacionarse, sin mediaciones, con la persona del Presidente. 
12. Recordemos, en fin, otro ejemplo de pulverización directamente ligado al anterior: grupos de mujeres en las comunidades con cierta cohesión histórica, o construida por circunstancias recientes, se asociaron en los años setenta y ochenta para administrar las comercializadoras de bienes de primera necesidad subsidiados gubernamentalmente. Ello no convenía obviamente al nuevo modelo de libre mercado e individualismo. Entonces se inventó la fórmula perfecta: credencializar el abasto (donde el abasto fue reducido, como decíamos, a tortillas, leche y desayunos escolares: el subsidio gubernamental a la extrema pobreza para evitar hambrunas, asociativismo o levantamientos). Se inventó "la mica", como se llamó en el medio popular, que podía ser insertada en el registrador de un molino de nixtamal, obteniendo un kilo de tortillas diario por familia; el molinero, a su vez, iba al banco con aquel aparato y le era liquidado el equivalente monetario a lo consumido en su negocio. ${ }^{9}$ ¿Qué espacio quedó, después de todo esto, para la organización colectiva de aquellas mujeres, en muchos casos cercanas a la iglesia, hay que dejarlo claro, que trataban por este medio de hacer frente a las necesidades de su colectividad, estableciendo por la misma vía un principio de autoridad moral y de reordenamiento comunitario? Ninguno.

13. El terreno de la religión y de las iglesias, en fin, no está exento de la tendencia. Hemos visto el juego gubernamental que consiste en reconocer a la iglesia católica apostólica y romana como la fuerte, mientras fomenta una proliferación irrefrenable de iglesias sin campanario, iglesias casi de cuadra, en contraposición o desavenencia unas con otras: protestantes en todas sus modalidades, evangélicos, presbiterianos, pentecostales, adventistas del séptimo día... En Chiapas Samuel Ruiz y los zapatistas han sido blanco de muchas de estas corrientes.

9 Gurza, Adrián, La restructuración de lo público : el caso de CONASUPO, (tesis profesional), México, unAM, ENEP Acatlán, 1995. 
El doble juego del estado en turno

Sería un error, en consecuencia, pensar que este desvanecimiento, esta difuminación de lo social y este debilitamiento de los órganos intermedios afecta de la misma manera al terreno estricto del Estado. Es cierto que en general el Estado se contrae y abandona enormes espacios que tienden a ser ocupados por monopolios, mafias y bandas atizando aún más la violencia generalizada. Pero no hay que perder de vista, al mismo tiempo, que el ascenso del desorden, la atomización y la violencia no implica para nada la pérdida de control del Estado sobre el proceso globalizador, ni una disminución de los beneficios del reducido grupo de actores privilegiados por dicho proceso.

Sucede más bien lo contrario, el debilitamiento de los espacios intermedios o públicos heredados por nuestra modernidad inacabada así como la atomización social contribuyen a que los mecanismos de dominación desde un pequeño núcleo se fortalezcan. Más allá de esta construcción decidida de dominación, el Estado se desentiende de enormes espacios en donde el orden se abandona a las fuerzas de la desconstrucción y en donde se cometen infinidad de injusticias no vigiladas ni castigadas.

14. Dentro de esta tendencia vemos que las policías se dividen, por una parte, en una colección indiscriminada de pequeños cuerpos que se confunden con la sociedad, la delincuencia

10 A este respecto nos informa Ruiz Harrel que el crecimiento de las policías de la capital de la República ha ido de la mano del crecimiento de la delincuencia, pero su ineficiencia también ha ido en aumento: mientras nosotros teníamos 65 policías por cada diez mil personas en 1994, París tenía 56, Roma 53, Madrid 44, Río de Janeiro 40, Washington 37 y Londres 25 policías por cada diez mil habitantes. Naturalmente que los salarios, la capacitación y el entrenamiento son tan malos que el medio está plagado de corrupción e ineficiencia; sociedad, delincuencia y policias se confunden y se autoanulan: en la capital mexicana para atrapar a cien delincuentes es necesario el trabajo anual de 1,295 policías, mientras en Washington sólo se necesitan 14, en París 15, en Londres 18, en Roma 21, en Nueva York 22, en Rio de Janeiro 30, en Sao Paulo 31 y en Madrid 35. Un solo policía del promedio de esas ciudades hace lo que 55 de los nuestros (Rafael Ruiz Harrel, Op. Cit., p. III). 
y las mafias, ${ }^{10}$ y por otro lado, en cuerpos selectos de altísima eficacia que tienden a concentrarse en aquellos puntos neurálgicos del orden globalizado que se vuelven puntos de gran tensión; estos cuerpos se confunden con los aparatos militares y paramilitares y al lado de ellos se concentran en la seguridad política, desmantelando a grupos opositores, armados o no, persiguiendo y pulverizando a las organizaciones y movimientos sociales, encargándose del narcotráfico para usufructuar de él, o para perseguirlo, cuando así lo indica la metrópoli mundial, y encargándose de la ingeniería electoral y de la persecución fiscal.

15. El propio Ejército se descompone en pequeñas unidades como nos lo hace saber el Centro de Derechos Humanos Fray Bartolomé de Las Casas en su Informe acerca de la guerra civil en la Zona Norte de Chiapas: "está claro que en Chiapas se está dando una disminución del tamaño de las unidades militares... De hecho en la Zona Norte la presencia militar no es numerosa, pero sí muy efectiva... La aplicación de la guerra de baja intensidad ha generado en las instituciones militares y en el aparato civil (ligado a ellas), la formación de fuerzas de elite, de comandos especiales, de grupos de alto rendimiento... que según los informes del Pentágono son ya un hecho en México y operan en Chiapas para instrumentar operativos quirúrgicos."11

Hay pues, cada vez de manera más evidente, un Estado en turno, con obligaciones hacia el exterior de la nación y hacia la economía globalizada que no puede descuidar un cierto orden, porque de ello depende la estabilidad económica del modelo globalizado, los préstamos, las inversiones... Y hay un Estado doméstico que se acerca cada vez más a lo que sería una mafia hegemónica en palacio, que actúa hacia el interior

11 Ni Paz Ni Justicia, Informe General y Amplio acerca de La Guerra Civil que sufren los Ch'oles en la Zona Norte de Chiapas, Centro de Derechos Humanos "Fray Bartolomé de Las Casas", San Cristóbal de Las Casas, octubre de 1996, p. 161. 
con toda impunidad mientras sus actos de corrupción no trasciendan al Newsweek, al Times o al Herald. Una vez terminado su mandato, si sus excesos no fueron extremos, a pesar de que sus cabezas visibles deben abandonar el país, sus negocios están establecidos y de su habilidad de grupo (de mafia), depende su subsistencia.

16. Las comunidades, los ciudadanos, se sienten abandonados, atacados por la delincuencia y por las propias bandas policiacas y tienden a organizarse también en bandas de autodefensa cuando el referente comunitario, la etnia, la tradición, el pueblo o el barrio así lo permiten. En estos casos los colectivos viven en una gran tensión debido al desempleo, los cambiantes roles entre géneros y la frustración producida por el acelerado desordenamiento de los referentes de tradición y futuro, los miembros de la comunidad se encuentran en peligro de desatar la violencia entre ellos mismos (pleitos juveniles, pleitos entre mujeres del bario, que en otras condiciones animarian actividades solidarias). El problema se agrava porque prácticamente desaparece la posibilidad de recurrir a un arbitro exterior que haga justicia, son terrenos de los que el Estado se ha retirado dejando a unas policías enredadas en la delincuencia, el chantaje y la extorsión. Entonces la comunidad tiende a reorganizarse emergentemente en guardias de autodefensa, o bien, sin llegar a ese punto, los pobladores tienden a hacerse justicia por propia mano, expulsando la mayoría de las veces a los propios cuerpos policiacos corruptos o dirigiendo su energía contra ellos. 12

12 René Girard, La Violence et le Sacré, Paris, Grasset, 1980, p. 30-32. En el estado de Morelos entre 1995 y 1996 se tuvo conocimiento de más de una decena de linchamientos en distintos poblados. La comunidad, agrega Girard, "busca canalizar hacia una víctima relativamente indiferente, una víctima 'sacrificable', una violencia que amenaza con desatarse entre sus propios miembros". 


\section{El gobierno cardenista del D.F.: un intento de "empoderamiento" local}

En diciembre de 1997 una nueva administración perteneciente al opositor Partido de la Revolución Democrática tomó posesión en el Distrito Federal y en sus delegaciones territoriales, proponiendo como uno de sus objetivos un plan de gobierno asentado en la participación ciudadana y, para ello, en la reorganización de los espacios de participación vecinal (en los barrios, los poblados, las unidades habitacionales, etc).

La enorme ciudad capital de México está dividida en 16 delegaciones territoriales de las cuales la mayor congrega a más de dos millones de habitantes. Las ideas de la participación ciudadana y de la descentralización administrativa han sido esgrimidas, desde la campaña política de Cuauhtémoc Cárdenas como la vía privilegiada para enfrentar los problemas urbanos en condiciones presupuestales reducidas en prácticamente un $40 \%$ con respecto a la última administración priísta (1994-1997).

El gobierno de la ciudad y muchos legisladores han estado de acuerdo en que el espacio privilegiado para la participación ciudadana es el de las unidades vecinales con identidad consistente, social y culturalmente hablando (el barrio, la colonia, la unidad habitacional, el poblado), en donde pueden expresarse con fuerza tanto los ciudadanos individualmente como los movimientos y organizaciones sociales, las ONG's, las asociaciones políticas, empresariales, religiosas, deportivas, etc. Dependiendo del tamaño de las delegaciones, el número de estas unidades vecinales oscilaría entre cien y quinientas.

Ahora bien, dado que con un número semejante de miembros es muy difícil llevar adelante los trabajos de un comité de representantes, se ha propuesto que los consejeros vecinales deberán congregarse en Consejos Sub-delegacionales, para discutir, clarificar y jerarquizar en su importancia los problemas y las demandas planteadas por la ciudadanía. 
Las experiencias mediterraneas y sudamericanas nos muestran que entre cien mil y doscientos mil habitantes es un número conveniente para descentralizar una serie de servicios (no todos naturalmente, y en la mayoría de las ocasiones, no los más costosos), y se ha puesto en evidencia igualmente que agregados poblacionales de estas dimensiones son los más adecuados para el fomento de la participación ciudadana. Una virtual división municipal del D.F. debería tender, por lo demás, a apoyarse en estas unidades subdelegacionales de entre cien $\mathrm{y}$ doscientos mil habitantes.

Porto Alegre en el Brasil, con un poco más de un millón de habitantes (tan grande como una delegación del D.F.), fue dividida en cerca de dieciséis zonas, buscando que el número de consejeros no excediera a las cuatro decenas y que el trabajo resultara lo más eficaz posible. Además, solamente en una época del año los consejeros se reúnen en ese plano más centralizado del concejo municipal; la mayoría del tiempo esos consejeros, incluso antes de ser elegidos, permanecen discutiendo los problemas en espacios muy descentralizados, muy enraizados en el nivel vecinal, en la pequeña región, en la colonia o conjunto de colonias con problemáticas homogéneas.

Hay que partir de un hecho radical: los ciudadanos no consideran la participación colectiva como algo atractivo: la gente no tiende a participar sino que en la mayoría de los casos tiende a refugiarse y a delegar sus responsabilidades en los líderes o los representantes, a menos que considere que algunos de sus problemas urgentes podrán ser resueltos con ese acto colectivo de participar. En Sudamérica se inventó la modalidad de destinar un reducido porcentaje del presupuesto municipal para que las juntas vecinales, después de un proceso muy bien normado, decidieran en qué debería ser invertido. En México nos hemos dado cuenta de que el llamado a la participación ciudadana encuentra oídos entre la gente cuando está asociado al tema de la seguridad y de la delincuencia en un espacio territorial definido (¿cómo tener control sobre la policía, cómo organizar una policía de barrio eficaz, cómo construir la defensa de la colonia, el barrio...?). 
Así pues, las experiencias asociativas exitosas demuestran que es indispensable servirse de ciertas "técnicas" para impulsar la participación, y de entre ellas destaca una buena práctica descentralizadora: conformar unidades territoriales que respeten la identidad poblacional pero que no sean tan pequeñas que reproduzcan al infinito los problemas, las demandas y las representaciones (o liderazgos personalizados) en cada pequeña colonia o condominio. Montevideo, a la llegada del Frente Amplio en los años ochenta, fue excesivamente descentralizada pero después de una rectificación el poco más de un millón que lo habita fue repartido en 18 circunscripciones.

Sin embargo, siendo realistas, la reconstrucción de lo local, de las identidades colectivas circunscritas, enfrenta problemas: en una sociedad como la de la Ciudad de México, debido a que la severa crisis económica ha mantenido estancados los índices de crecimiento durante los últimos quince años (debido al desordenamiento social que la globalización ha acarreado y debido a los elevados índices de violencia e inseguridad ciudadana que de ahí resultan), los habitantes de este enorme conglomerado adoptan medidas muchas veces contradictorias entre sí. A veces se refugian en posiciones defensivas privatizantes (vemos como colonias de clase media, viviendas unifamiliares, condominios, unidades habitacionales, fraccionamientos privados... están cerrando aceleradamente sus calles, poniendo rejas por todos lados, ensayando todos los sistemas de alarmas); pero en otras ocasiones observamos que la creciente masa recrea de manera alarmante formas organizacionales defensivas, verticales, tributarias de un número cada vez mayor de liderazgos que supuestamente les garantizan que "alguien" se encargará de gestionar la solución de algunos de sus problemas urgentes (esta última forma organizativa se encuentra privilegiada, como es obvio, en los espacios de mayor precariedad y en los más tradicionales, que coinciden con las colonias de asentamiento relativamente reciente o bien con los pueblos de gran tradición, etc.).

Ante la atomización privatizante, de un lado, y el neo-patrimonialismo, del otro, se ven erosionados los espacios de la 
democracia social, aquellos que verdaderamente fortalecen el asociativismo de la sociedad civil, el verdadero embarnecimiento social.

Participación y seguridad: lo público y lo privado.

Cuahtémoc Cárdenas concentró su campaña triunfadora en la consigna "jJuntos! gobernaremos; un programa para que la gente, de manera organizada y en coordinación con las autoridades gubernamentales, haga frente a los problemas más apremiantes de su entorno vital".

Pero han comenzado a enfrentarse las dificultades que conlleva esa fórmula aparentemente sencilla aunque esencial. Resulta que desde el momento en que la cuestión de la seguridad se destacó en las encuestas como la preocupación número uno de la ciudadanía, Cárdenas ligó inteligentemente su programa de seguridad al objetivo de la participación ciudadana: "se trata, explicó, de un programa preventivo que se basa en la descentralización, en la asignación de responsabilidades territoriales y en la convocatoria a la participación ciudadana... integrar consejos vecinales que promuevan la seguridad de las colonias... La única forma de acabar las complicidades entre policías y ladrones es establecer una instancia que vigile a ambos, y en ella el papel protagónico obviamente lo tiene la ciudadanía”.

Ahora bien, pronto surgió una dificultad al tratar de articular la participación ciudadana y la seguridad: el acuerdo principal que hubo entre parlamentarios, partidos, gobierno y ciudadanos en las discusiones en torno a la nueva Ley de Participación Ciudadana fue, como ya decíamos, que la colonia , el barrio, el poblado o la unidad habitacional debían ser los espacios territorializados de identidad consistente a fortalecer ya que sólo ahí es posible hacer florecer la vida asociativa y los procesos generadores de ciudadanía. Siguiendo este principio cada una de las 16 delegaciones políticas del DF, contarian con entre 100 y 500 unidades vecinales con estas características. 
Sin embargo, ya en la práctica los agregados espontáneos en que los ciudadanos han comenzado a asociarse para enfrentar el problema de la inseguridad y la delincuencia tienden hacia unidades asociativas mucho más pequeñas que las antes mencionadas: en una misma unidad habitacional ellos se organizan por andadores o por grupos de vivienda extremadamente restringidos, o bien, familias de clase media con viviendas unifamiliares no quieren saber nada de una pequeña unidad habitacional con la que colindan y con la que prácticamente se traslapan o, en fin, los habitantes de un conjunto de apenas cuatro cuadras se dividen en dos grupos y en lugar de dos enrejados tienen que poner cuatro, porque unos comerciantes a la mitad de ese conjunto se oponen a quedar aislados de su potencial clientela. A ese ritmo, en lugar de 30 ó 50 unidades vecinales en promedio por cada 100 mil habitantes podrían llegar a ser 500 o más microuniversos privatizantes y aislados. ¿Cuál es el sentido de esa pulverización? Sin duda el miedo, la violencia, la delincuencia y el sentido común con que el ciudadano deja de creer en la solidaridad y en las estadísticas sospechosamente tranquilizadoras.

Y es que los datos son aplastantes: si es cierto que la delincuencia denunciada entre 1993 y 1996 se multiplicó 80\% en el Distrito Federal y $92 \%$ en el resto de la República y que solamente 29 de cada mil delitos registrados (3\%) en 1996, terminaron con la captura del presunto responsable y su presentación ante un juez penal, ${ }^{13}$ entonces, en efecto, todo se estaría acercando a un escenario des-institucionalizante, por llamarlo de alguna manera, en donde los ciudadanos individualmente no tienen ninguna fuerza, los contratos no cuentan con ningún respaldo que los haga respetables y, en una palabra, el principio civilizatorio estaría siendo debilitado.

Cuando se discute con los vecinos es muy difícil encontrar argumentos para convencerlos de que no se encierren, al menos no en espacios tan pequeños e irracionales, como los

13 Ruiz Harrel, Rafael, "La zona metropolitana: un reporte", Reforma, 21 de octubre, 1996, p.2b. 
descritos, pues en el mediano plazo no tendrán dinero ni para pagar la vigilancia en el interior de sus enrejados y, además, en muchas ocasiones esos mismos vigilantes se encargan de robarlos, porque conocen con precisión el funcionamiento del microvecindario.

Estamos aquí, pues, frente al problema de cómo conciliar espacios de participación y espacios de seguridad ciudadana ya que es claro que en un caso estamos hablando de la extensión y el fortalecimiento de la vida pública y asociativa y en el otro, en la mayoría de los casos, estamos recreando fantasmas, huyendo, encerrándonos (en el extremo frente a la televisión), y que con esa actitud muy poco ayudamos a enfrentar nuestros problemas. La inseguridad es un asunto público que ha demostrado no encontrar solución si se privatiza o se individualiza. Pero también es cierto, qué duda cabe, que si los programas de participación ciudadana y de prevención de la delincuencia no avanzan palpablemente, como parece estar siendo el caso en el primer año de gobierno perredista en el Distrito Federal, los ciudadanos no tienen por qué dar crédito a supuestas soluciones que van más allá de su pequeño vecindario.

Esto último nos permite profundizar en nuestro tema de partida. En efecto, vemos que ante los intentos de regeneración del tejido asociativo se oponen una serie de tendencias que al inicio de este ensayo calificábamos como desorganizadoras. En realidad ahora podemos decir que ante los intentos de reconstrucción de la vida pública aparecen fuerzas privatizantes, atomizantes, en una palabra, pulverizadoras. Habría disolvencia y atomización debido a las velocidades inusitadas a que están siendo sometidas las culturas societales (particularmente las más expuestas a los inmisericordes acelerones y frenones de la modernización y de la economía abierta); arranque y freno, alteración constante del ritmo, desbalance, pedacería en medio de la pobreza de recursos, expulsión de los hombres de sus medios originales sin que sean reabsorbidos en los puntos de llegada son conceptos poco eleborados, es cierto, pero los únicos con los que podemos dar cuenta del panorama social de nuestra época. 


\section{Conclusiones}

Es cierto que en muchas sociedades el repentino retiro por parte del Estado de sus tradicionales funciones asistenciales y la destrucción de los espacios, órganos e instituciones de intermediación ha sido salvaje y en muy corto tiempo. Sin embargo, en el caso de México, el impacto desorganizador y la posibilidad de una escalada de violencia degenerativa pueden ser mayores debido a que se trata de una sociedad cuyo orden históricamente ha dependido, quizás de manera más estricta que ninguna otra (con excepciones como las de China, Francia o Rusia), del rol central y ordenador del Estado.

Se trata dicho resumidamente, de una cultura y un orden político-estatales que nos enseñan por experiencia que cada vez que este último actor central se ha visto debilitado, las tendencias disgregadoras, desordenadoras y violentas se han desatado incontrolablemente hasta que un nuevo actor reordenador y necesariamente autoritario restablece una paz vertical incontestada; así pasó en la Guerra de Independencia, en las guerras de Reforma, en la Revolución Mexicana y así parece aterradoramente comenzar a dibujarse hoy en este país, "dirigido" fatalmente por una élite sin experiencia política y sin cultura nacional.

Se nos dirá que países como Colombia nos llevan mucho terreno andado en esta dirección y que la situación no ha degenerado dramáticamente por la derivada catastrofista que aquí estamos evocando. Pero justamente una sociedad como la colombiana, por contraste, permite clarificar lo que hemos intentado exponer. En efecto, ahí todo resultó al revés con respecto a la historia mexicana: las oligarquias regionales subsistieron con fuerza hasta el presente, la guerra exterior y en consecuencia el llamado reiterativo a las masas de la nación no fue un factor definitiorio en la historia de aquel país, los sectores populares siempre se mantuvieron en un cierto encuadre gracias a la intermediación constante de los grupos dominantes regionales y todo ello redundó en déficits constantes en la constitución del Estado central. El propio síndrome 
de Colombia que ha sido la violencia, como nos dice Daniel Pecaut, ${ }^{14}$ siempre se ha mantenido como un factor de desordenamiento local-regional y no tanto como una amenaza de desorden generalizado en el plano de la nación. Hay pues en el caso colombiano una dispersión regional, pero esta imagen guarda mucha distancia con respecto a la idea de atomización y pulverización de lo social.

Concluyamos también diciendo que nuestra sociedad, maltrecha como nunca, permite hoy una doble lectura, contradictoria, casi esquizofrénica: es, por una parte, la sociedad del desorden, de la atomización, de la fragmentación salvaje, de la generación exponencial de pobres y de los más poderosos ricos de nuestra época, de la anomia social, de la delincuencia generalizada, de la narcopolítica, de la militarización del Sureste mexicano y de la más horrenda corrupción gubernamental.

Pero es, sin duda por lo mismo, la tierra de las más grandes esperanzas, la del zapatismo y la del cardenismo, la de la búsqueda desesperada por recomponer las identidades locales, circunscritas, por "empoderar" a la sociedad, por encontrar un camino que nos permita vencer la impotencia, que atempere a esos poderes inconmensurables que van por todas las venas, desde Washington y las grandes trasnacionales e instituciones financieras, pasando por las televisoras, las radios, las universidades, los intelectuales... hasta los más recónditos poblados del Sureste en donde fuerzas militares que parecen de otro país persiguen y aniquilan a los liderazgos, municipios, organizaciones sociales.

Un hecho es importante en medio de todo esto: la mitad de los ciudadanos de la capital de México sintieron que ganaron las elecciones porque Cárdenas recibió la mitad de los votos y tres de cada cuatro sintieron que las cosas mejorarian porque apostaron por el cambio. En esta perspectiva, si el primer año del nuevo gobierno no demuestra que las cosas son diferentes

14 Daniel Pécaut, "Violencia y política en Colombia", en Democracia, etnicidad y violencia politica en los países andinos, Instituto Francés de Estudios Andinos e Instituto de Estudios Peruanos, Perú, 1993, p.273. 
o que al menos se está intentando que las cosas sean diferentes se verá inhibida su euforia participativa y crítica y los veremos relegarse en la indiferencia y la apatía. Entonces, el espacio estará abonado para que las cosas no sólo no cambien sino se alejen del objetivo de enfrentar asociativamente los problemas colectivos y los peligros serán enormes de ver reproducida una relación lider-masas, el regreso de los liderazgos personalizados en lugar del fortalecimiento de la sociedad civil. 